\title{
Fractionation of the Providencia stuartii Cell Envelope
}

\author{
By IAN CHOPRA* AND SUSAN C. JOHNSON \\ Department of Microbiology, The Medical School, University of Bristol, Bristol BS8 ITD, UK
}

(Received 14 November 1986; revised 19 February 1987)

\begin{abstract}
Cell envelopes (i.e. unfractionated inner and outer membranes) were obtained from Providencia stuartii by following procedures previously applied to the isolation of envelopes from Escherichia coli. The $P$. stuartii envelopes contained known inner membrane enzymes that included a variety of dehydrogenases and ATPase. The catalytic activity of the ATPase depended upon the concentration of magnesium ions, the substrate (ATP) level and the ratio of magnesium ions to ATP. Cell envelopes from $P$. stuartii were further fractionated to recover inner and outer membrane polypeptides by treatment with the detergent Sarkosyl. Proteins from the periplasmic region were recovered by a simple osmotic shock procedure also previously applied to $E$. coli. The purity of the various $P$. stuartii cell envelope fractions was assessed by a combination of techniques that included one- and two-dimensional gel electrophoresis of proteins, enzyme assays and detection of penicillin-binding proteins.
\end{abstract}

\section{INTRODUCTION}

Many recent investigations have been directed towards elucidation of cell envelope structure in Gram-negative bacteria (Owen et al., 1982; Lugtenberg \& Van Alphen, 1983). These studies arise in part from the need to understand the role of cell envelopes in the pathogenesis of bacterial infections and the manner by which cell envelope composition influences antibiotic susceptibility (Chopra \& Ball, 1982; Lugtenberg \& Van Alphen, 1983; Nikaido \& Vaara, 1985). Although extensive genetic and biochemical studies have been conducted on cell envelopes from a wide variety of Gram-negative bacteria (Owen et al., 1982; Lugtenberg \& Van Alphen, 1983), there are notable exceptions. The Gram-negative bacterium Providencia stuartii is one such exception.

In this paper we describe methods for the fractionation of the $P$. stuartii cell envelope. These methods may provide the starting point for future studies on pathogenicity and antibiotic resistance in this organism which is an important cause of urinary tract infection, particularly in long-term catheterized patients (Hawkey, 1984; Warren, 1986).

\section{METHODS}

Bacterial strains and growth conditions. Experiments were done with $P$. stuartii strains P308 and P306 (Hawkey et al., 1985; Chopra et al., 1987). The latter carries the plasmid pUB2660, which encodes a TEM2-type $\beta$-lactamase (Hawkey et al., 1985). Bacteria were grown aerobically at $37^{\circ} \mathrm{C}$ either in a nutrient broth (Lab M broth; London Analytical and Bacteriological Media) or on nutrient agar (Lab M agar; London Analytical and Bacteriological Media).

Preparation of cell envelopes and fractionation to yield inner and outer membrane polypeptides. Total cell envelopes were prepared from $P$. stuartii by following a procedure based on that of Tsuchiya \& Rosen (1975a), originally developed for isolation of envelopes from $E$. coli. The method was modified slightly in that bacteria were disintegrated by sonication instead of by passage through a French press, mercaptoethanol was replaced by

Abbreviation: PBP, penicillin-binding protein. 
dithiothreitol $(2 \mathrm{mM})$ and membranes were stored at $-70^{\circ} \mathrm{C}$ in small portions. Inner and outer membrane polypeptides were fractionated after treating cell envelopes with the detergent Sarkosyl (Filip et al., 1973; Chopra \& Shales, 1980).

Preparation of periplasmic and cytoplasmic fractions. Periplasmic proteins were obtained from $P$. stuartii by an osmotic shock procedure (Heppel, 1968). Cytoplasmic fractions were obtained by sonication of osmotically shocked bacteria that had been washed to remove released periplasmic proteins. After sonication, cell envelopes (and unlysed cells) were removed by centrifugation $\left(85000 \mathrm{~g}, 4{ }^{\circ} \mathrm{C}, 3 \mathrm{~h}\right.$ ) and the supernatant containing cytoplasmic contents was retained.

Protein determinations. Protein was determined using the Folin-Ciocalteu reagent according to Herbert et al. (1971).

Electrophoresis of polypeptides and determinations of isoelectric point and molecular mass. One- and twodimensional electrophoresis of both radio-labelled and non-labelled proteins was done as previously described (Dixon \& Chopra, 1986). The isoelectric points of uncharacterized proteins were determined as described by Ames \& Nikaido (1976). Molecular masses of uncharacterized proteins were calculated by constructing calibration curves of log molecular mass versus distance migrated for polypeptides of known molecular mass (Hames \& Rickwood, 1981). A computer program for regression analysis was used to process the data. Scanning densitometry of separated polypeptides was done with a Joyce-Loebl Chromoscan 3 equipped with automated peak integration facilities.

Detection of penicillin-binding proteins (PBPs). Cell envelopes from $P$. stuartii were treated for 10 min with benzyl[ $\left.{ }^{14} \mathrm{C}\right]$ penicillin [potassium salt, $50 \mathrm{mCi} \mathrm{mmol}^{-1}\left(1.85 \mathrm{GBq} \mathrm{mmol}^{-1}\right)$, Amersham] as described by Spratt (1977). The reaction was terminated by the addition of non-radioactive benzylpenicillin and Sarkosyl (Spratt, 1977). PBPs were resolved by slab gel electrophoresis according to Suzuki et al. (1978) and detected by fluorography (Chamberlain, 1979).

Enzyme assays. $\beta$-Lactamase, ATPase, succinic-, NADH-, lactate-, malate-, and glycerol-3-phosphatedehydrogenases were assayed at $37^{\circ} \mathrm{C}$ following previously published procedures (Tsuchiya \& Rosen, $1975 b$; Shohayeb \& Chopra, 1985; Dixon \& Chopra, 1986). With the exception of ATPase, the rates of the enzymic reactions were monitored continuously in a Pye Unicam PU8800 spectrophotometer, which was coupled to a micro-computer equipped with Pye Unicam kinetics software, permitting rate calculations by least squares fit (see Chopra, 1986).

\section{RESULTS}

\section{Preparation of cell envelopes and assays for known membrane enzymes}

Cell envelopes (i.e. material containing both inner and outer membranes) provide the usual starting material for biochemical studies on Gram-negative membrane structure (Owen et al., 1982). It was therefore important to establish that such material could be prepared from $P$. stuartii. Cell envelopes were easily obtained from $P$. stuartii by following the procedure of Tsuchiya \& Rosen (1975a), a method originally devised for use with $E$. coli. Experiments involving the $\beta$-lactamase producing $P$. stuartii strain PV306 showed that the final washed envelope preparation contained $<0.5 \%$ of the total cellular $\beta$-lactamase content. This indicates negligible contamination of $P$. stuartii envelopes with soluble protein.

In order to establish that the envelopes retained biological activity a number of enzymes known to be envelope associated in other Gram-negative bacteria were assayed in $P$. stuartii cell envelope preparations. The following enzymes were detected [nmol substrate utilized $\mathrm{min}^{-1}(\mathrm{mg}$ envelope protein) $)^{-1} \pm \mathrm{SD}, n=3$ ]: ATPase, $285.8 \pm 7 \cdot 1$ (in the presence of $1 \mathrm{mM}-\mathrm{Mg}^{2+}$ and $6 \mathrm{mM}$-ATP); glycerol-3-phosphate dehydrogenase, $14.2 \pm 0.7$; lactate dehydrogenase, $7.9 \pm 0.3$; malate dehydrogenase, $3.6 \pm 0.1 ; \mathrm{NADH}$ dehydrogenase, $134.2 \pm 5.4$; and succinate dehydrogenase, $103.5 \pm 0 \cdot 7$. It is well known that the catalytic activity of bacterial ATPases are influenced by the substrate (ATP) level and the concentration of magnesium ions (Downie et al., 1979). The activity of the $P$. stuartii ATPase was also dependent upon these parameters (Fig. 1). These data concerning ATPase catalytic activity provide further evidence for the authenticity of the $P$. stuartii cell envelope material.

\section{Treatment of $P$. stuartii cell envelopes to recover outer and inner membrane polypeptides}

One of the simplest methods for separating inner and outer membrane polypeptides in bacteria such as $E$. coli depends upon the selective solubilization of inner membranes by the detergent Sarkosyl (Chopra \& Shales, 1980; Owen et al., 1982). P. stuartii cell envelopes were 


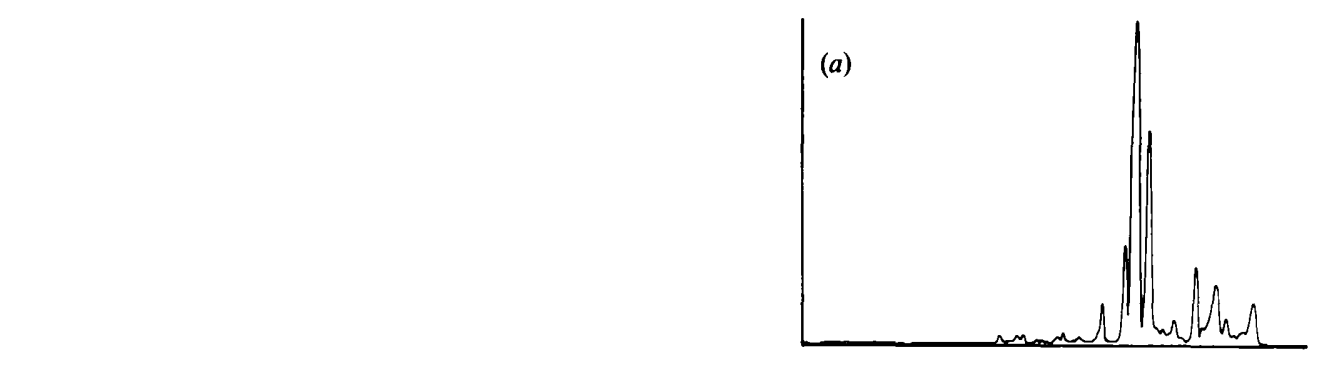

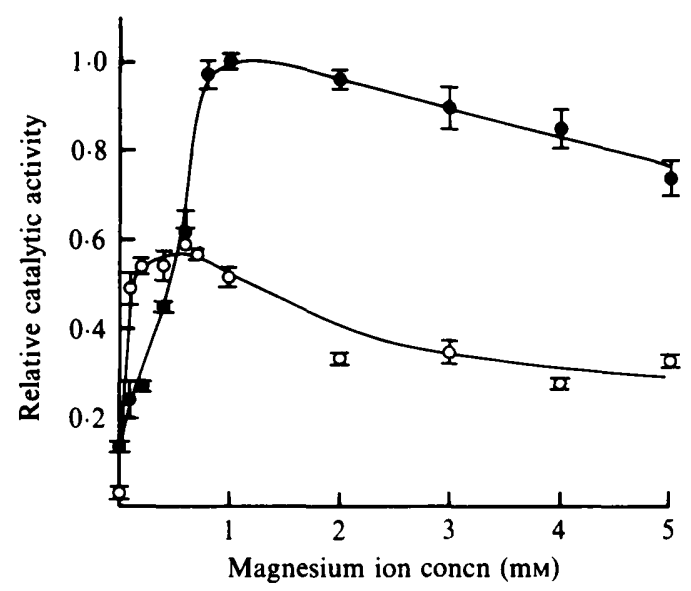

Fig. 1
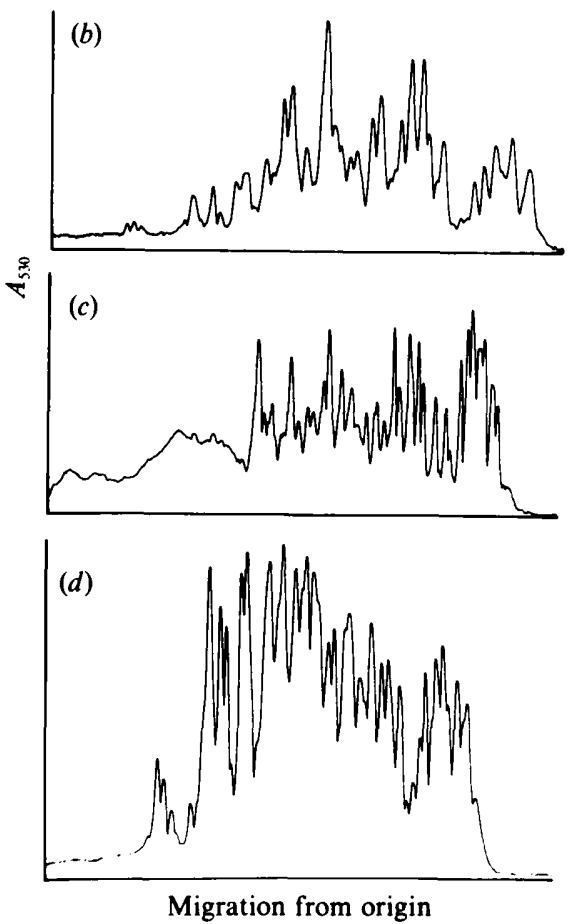

Fig. 2

Fig. 1. Effect of substrate and magnesium ion concentrations on the activity of ATPase from $P$. stuartii PV308. ATPase assays were performed as described in Methods using ATP concentrations of $2 \mathrm{mM}(\mathrm{O})$ and $6 \mathrm{mM}(\mathrm{O})$. The absolute value corresponding to the relative activity of 1 is $285.8 \mathrm{nmol}$ ATP utilized $\mathrm{min}^{-1}$ (mg envelope protein) ${ }^{-1}$ at $37^{\circ} \mathrm{C}$. Error bars denote $\pm \mathrm{SD}$, values are from triplicate determinations on a single envelope preparation.

Fig. 2. Scanning densitometer profiles of polypeptides in various fractions derived from $P$. stuartii PV 308. Peaks to the left have higher molecular masses than those to the right, the range being approximately $200 \mathrm{kDa}$ (left) to $10 \mathrm{kDa}$ (right). (a) Sarkosyl-insoluble material derived from cell envelopes; $(b)$ material released from osmotically shocked bacteria; $(c)$ Sarkosyl-soluble material derived from cell envelopes; $(d)$ soluble material obtained after removal of fractions $(a)-(c)$ above.

extracted with Sarkosyl and detergent-soluble and detergent-insoluble proteins recovered. Electrophoretic analysis of these fractions demonstrated that their polypeptide composition differed fundamentally (Fig. 2a,c). In particular, the Sarkosyl-insoluble material contained three major polypeptides in the $30-40 \mathrm{kDa}$ region (polypeptides $12-14$, in Fig. $3 a$ ) not found in the Sarkosyl-soluble material (cf Fig. 2a,c). Two-dimensional electrophoresis of Sarkosylinsoluble material demonstrated that the major polypeptides (i.e. 12-14) were acidic (Fig. $3 b$ ) with isoelectric points in the range 4.8-5.1. In all bacteria so far examined, PBPs are located in the cytoplasmic membrane (i.e. the Sarkosyl-soluble fraction). Several PBPs were detected in the cell envelope of $P$. stuartii PV308 (Fig. 4). 
(a)

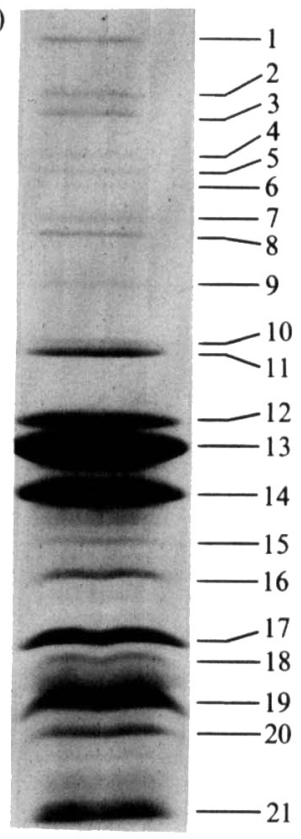

(b)

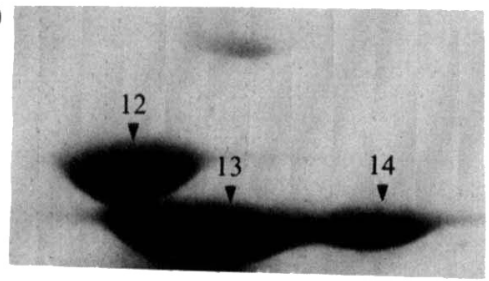

Fig. 3

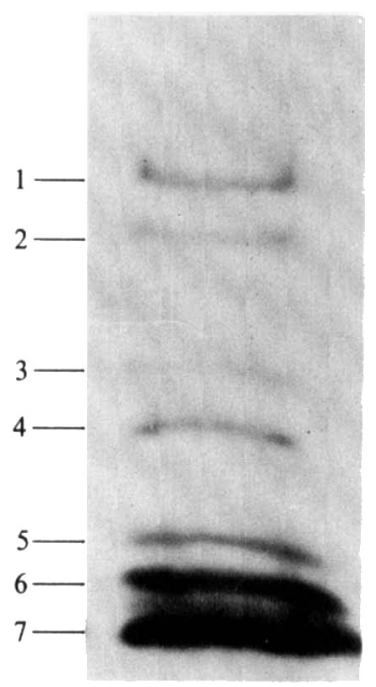

Fig. 4

Fig. 3. Separation of polypeptides from the outer membrane of $P$. stuartii PV308. Outer membranes were prepared by treatment of cell envelopes with Sarkosyl and proteins were analysed by electrophoresis. (a) One-dimensional electrophoresis; those polypeptides (1-21) reproducibly identified are labelled to the right of the profile. The molecular masses of the resolved polypeptides fall between $120 \mathrm{kDa}$ (top) and $10 \mathrm{kDa}$ (bottom). (b) Two-dimensional electrophoresis. The $\boldsymbol{P}$. stuartii outer membrane polypeptides 12,13 and 14 are shown, which have pI values of $4 \cdot 8,4.9$ and $5 \cdot 1$ respectively.

Fig. 4. Separation of PBPs from the envelope of $P$. stuartii PV308. Envelopes were prepared and treated with benzyl[ $\left.{ }^{14} \mathrm{C}\right]$ penicillin as described in Methods. PBPs were detected by fluorography after separation of membrane proteins by electrophoresis (see Methods). The PBPs are numbered from the highest molecular mass (PBP 1, 88 kDa) to the lowest (PBP 7, $42 \mathrm{kDa}$ ).

The molecular masses of the PBPs were as follows: PBP 1, $88 \mathrm{kDa}$; PBP 2, $78 \mathrm{kDa}$; PBP 3, $64 \mathrm{kDa}$; PBP 4, $58 \mathrm{kDa}$; PBP 5, $47 \mathrm{kDa}$; PBP 6, $43 \mathrm{kDa}$; and PBP 7, $42 \mathrm{kDa}$. These molecular masses were calculated by direct comparison (i.e. co-electrophoresis) with $E$. coli PBPs, and using the molecular masses quoted for $E$. coli PBPs by Boulton \& Orr (1983). The $P$. stuartii PBPs all separated into the Sarkosyl-soluble fraction with no detectable quantities in the Sarkosylinsoluble fraction (data not shown). These experiments suggest that treatment of $P$. stuartii cell envelopes with Sarkosyl achieves inner and outer membrane protein separation with an efficiency comparable to that in $E$. coli.

\section{Recovery of periplasmic proteins from P. stuartii}

Proteins were released from $P$. stuartii by the osmotic shock procedure of Heppel (1968). Onedimensional electrophoresis showed that the proteins released (Fig. $2 b$ ) differed from those in 


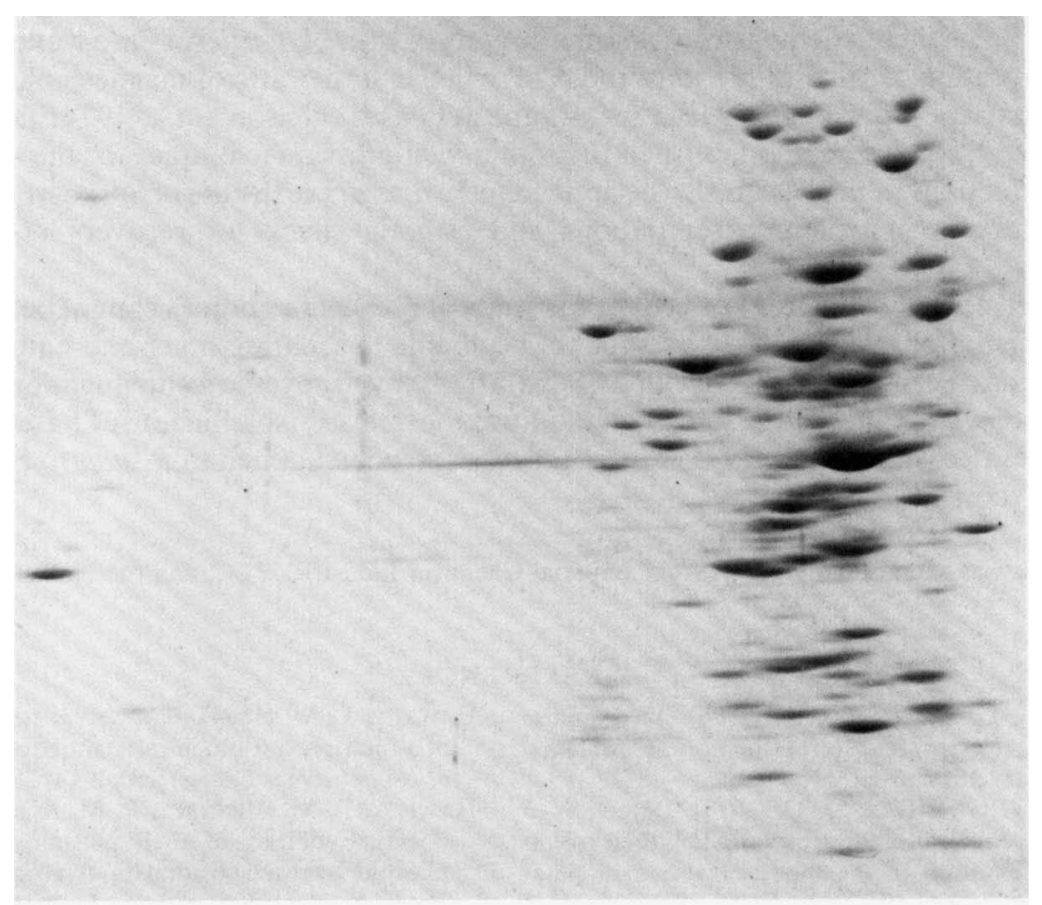

Fig. 5. Two-dimensional electrophoretic separation of polypeptides released by osmotic shock from $P$. stuartii PV308. Acidic polypeptides are located to the left and basic polypeptides to the right, the range of pI values being 4.8 (left) to $7 \cdot 1$ (right). High molecular mass polypeptides are located at the top, and low molecular mass components at the bottom, the range being $180 \mathrm{kDa}$ (top) to $10 \mathrm{kDa}$ (bottom).

the outer and inner membrane fractions (Fig. $2 a, c$ ) and also from the proteins in the fraction defined as cytoplasmic contents (Fig. $2 d$ ). Furthermore, when the $\beta$-lactamase-producing strain P306 was subjected to osmotic shock, the material released contained a high enzyme specific activity (data not shown). The proteins released by osmotic shock from $P$. stuartii therefore appear to be derived principally from the periplasmic region. Further evidence for this was provided by two-dimensional gel electrophoresis of proteins released by osmotic shock (Fig. 5). The polypeptide profile of the material released by osmotic shock differed from the profiles obtained with other cell fractions (data not shown). In particular, the osmotic shock procedure did not appear to cause substantial release of outer membrane proteins because the characteristic major acidic polypeptides of the outer membrane (12-14, Fig. 3b) were not detected in the proteins released by osmotic shock (Fig. 5).

\section{DISCUSSION}

Several aspects of the biology of $P$. stuartii have been examined in detail, but not, apparently, the nature of its cell envelope (Hawkey, 1984; Warren, 1986). This paper has presented data concerned with the latter.

Since $P$. stuartii is a Gram-negative rod, we anticipated that methods applicable to cell envelope fractionation in $E$. coli might also be successful when applied to $P$. stuartii. As noted by Owen et al. (1982), procedures for bacterial membrane isolation should be designed in such a way as to retain the membrane in its 'native' state and to remove as far as possible material originating from other cell compartments. We have demonstrated that it is possible to obtain $P$. stuartii cell envelopes that retain membrane enzyme activity and that are not contaminated with soluble proteins by following the procedures of Tsuchiya \& Rosen (1975a), originally devised for 
$E$. coli. Apart from demonstrating that envelopes contained characteristic membrane enzymes, we were able further to demonstrate that the activity of the $P$. stuartii ATPase was dependent on the concentration of magnesium ions, the ATP level, and the ratio of magnesium ions to ATP, features that are typical of bacterial membrane ATPases (Nelson et al., 1974; Downie et al., 1979). In addition we have established that other well-proven techniques for the separation of envelope fractions in $E$. coli can also be applied to $P$. stuartii i.e. the use of Sarkosyl for inner and outer membrane polypeptide separations and osmotic shock for recovery of periplasmic proteins.

However, some procedures devised for the study of $E$. coli membranes cannot be used directly for $P$. stuartii. For instance, we have not yet been able to separate inner and outer membrane vesicles from $P$. stuartii cell envelope preparations by isopycnic centrifugation on sucrose gradients (Owen et al., 1982), and a method used to release (solubilize) ATPase from $E$. coli membranes (Rosen \& Alder, 1975) was not successful when applied to $P$. stuartii cell envelopes (data not shown).

This work was supported by grants from Imperial Chemical Industries PLC, and the Nuffield Foundation.

\section{REFERENCES}

AmES, G. F. L. \& Nikaido, K. (1976). Two-dimensional gel electrophoresis of membrane proteins. Biochemistry 15, 616-623.

Boulton, M. G. \& ORR, D. C. (1983). Detection of bacterial penicillin-binding proteins and their role in the interpretation of the mode of action of betalactam antibiotics. In Antibiotics: Assessment of Antimicrobial Activity and Resistance (Society for Applied Bacteriology Technical Series no. 18), pp. 161181. Edited by A. D. Russell \& L. B. Quesnel. London \& New York: Academic Press.

Chamberlain, J. P. (1979). Fluorographic detection of radioactivity in polyacrylamide gels with the water soluble fluor, sodium salicylate. Analytical Biochemistry 98, 132-135.

ChOPRA, I. (1986). A soft touch with kinetics. Laboratory Practice 35, 17-18.

Chopra, I. \& Ball, P. R. (1982). Transport of antibiotics into bacteria. Advances in Microbial Physiology 23, 183-240.

Chopra, I. \& Shales, S. W. (1980). Comparison of the polypeptide composition of Escherichia coli outer membranes prepared by two methods. Journal of Bacteriology 144, 425-427.

Chopra, I., Johnson, S. C. \& Bennett, P. M. (1987). Inhibition of Providencia stuartii cell envelope enzymes by chlorhexidine. Journal of Antimicrobial Chemotherapy 19, 743-752.

Dixon, R. A. \& ChoprA, I. (1986). Leakage of periplasmic proteins from Escherichia coli mediated by polymyxin B nonapeptide. Antimicrobial Agents and Chemotherapy 29, 781-788.

Downie, J. A., Gibson, F. \& Cox, G. B. (1979). Membrane adenosine triphosphatases of prokaryotic cells. Annual Review of Biochemistry 48, 103-131.

Filip, C., Fletcher, G., WulfF, J. L. \& Earhart, C. F. (1973). Solubilization of the cytoplasmic membrane of Escherichia coli by the ionic detergent sodium-lauryl sarcosinate. Journal of Bacteriology 115, 717-722.

HAMEs, B. D. \& RickwoOd, D. (1981). Gel Electrophoresis of Proteins: a Practical Approach. London \& Washington: IRL Press.
Hawkey, P. M. (1984). Providencia stuartii: a review of a multiply antibiotic-resistant bacterium. Journal of Antimicrobial Chemotherapy 13, 209-226.

HaWkey, P. M., BennetT, P. M. \& HaWkey, C. A. (1985). Evolution of an $\mathbf{R}$ plasmid from a cryptic plasmid by transposition of two copies of $\mathrm{Tn} l$ in Providencia stuartii. Journal of General Microbiology 131, 927-933.

HePpel, L. A. (1968). Preparation of cells of Escherichia coli with altered permeability. Methods in Enzymology 12B, 841-846.

Herbert, D., Phipps, P. J. \& Strange, R. E. (1971). Chemical analysis of microbial cells. Methods in Microbiology 5B, 209-344.

LUGTENBeRG, B. \& VAN Alphen, L. (1983). Molecular architecture and functioning of the outer membrane of Escherichia coli and other Gram-negative bacteria. Biochimica et biophysica acta 737, 51-115.

Nelson, N., KanNer, B. I. \& GuTNICK, D. L. (1974). Purification and properties of $\mathbf{M g}^{2+}-\mathrm{Ca}^{2+}$ adenosinetriphosphatase from Escherichia coli. Proceedings of the National Academy of Sciences of the United States of America 71, 2720-2724.

Nikaido, H. \& VaARA, M. (1985). Molecular basis of bacterial outer membrane permeability. Microbiological Reviews 49, 1-32.

Owen, P., Graeme-Cook, K. A., Crowe, B. A. \& CoNDON, C. (1982). Bacterial membranes: preparative techniques and criteria of purity. Techniques in Lipid and Membrane Biochemistry B407b, 1-69.

Rosen, B. P. \& ADLER, L. W. (1975). The maintenance of the energized membrane state and its relation to active transport in Escherichia coli. Biochimica et biophysica acta 387, 23-36.

ShohaYeB, M. \& ChOpRA, I. (1985). Composition of membranes from whole cells and minicells of Bacillus subtilis. Journal of General Microbiology 131, 345-354.

SPratT, B. G. (1977). Properties of the penicillinbinding proteins of Escherichia coli K-12. European Journal of Biochemistry 72, 341-352.

Suzuki, H., Nishimura, Y. \& Hirota, Y. (1978). On the process of cellular division in Escherichia coli: a 
series of mutants of $E$. coli altered in the penicillinbinding proteins. Proceedings of the National Academy of Sciences of the United States of America 75, 664-668.

TsuchIYA, T. \& Rosen, B. P. (1975a). Characterization of an active transport system for calcium in inverted membrane vesicles of Escherichia coli. Journal of Biological Chemistry 250, 7687-7692.

TSUCHIYA, T. \& RosEN, B. P. (1975b). Restoration of active calcium transport in vesicles of an $\mathrm{Mg}$ ATPase mutant of Escherichia coli by wild-type MgATPase. Biochemical and Biophysical Research Communications 63, 832-838.

Warren, J. W. (1986). Providencia stuartii: a common cause of antibiotic-resistant bacteriuria in patients with long-term indwelling catheters. Reviews of Infectious Diseases 8, 61-67. 